\title{
Leadership Development Programs to Integrate Business and People - Continuous Journey
}

\author{
Soumya R. S. ${ }^{1}$, Dr. M. M. Bagali ${ }^{2}$ \\ ${ }^{1} \mathrm{Ph} . \mathrm{D}$, Student, Jain University, Bangalore-560056, India
}

${ }^{2}$ Professor, Management, Head-Ph.D., Program in Management, Jain University, Bangalore- 560078, India

\begin{abstract}
Leadership development aims at developing set of people to expand the collective capacity of leaders at all job level, so that they can engage, co-create and effectively handle overall business outcome. In today's globally competitive environment, Leadership development has become the necessity than a choice for organization(s) which are looking at sustained business growth irrespective of its presence in either global or local market. Till few years back, leadership development was seen as a training intervention to develop class of management members to showcase them as role model for rest of the organization. In today's context, organizations which are well focused, have realized that leadership development is organization-wide spread over activity across various levels and the real success comes through commitment of organization, people (talent) and business (market), in developing dynamic leadership. This Research paper discusses that Leadership Development is incomplete, if the development does not cover leadership influence on positive business performance and consistency in people engagement. The author has attempted to design a global Leadership Development Model - BULP (Business Umbrella for Leadership Program) ${ }^{1}$. The model is the outcome of a detailed research study done in Bangalore ${ }^{2}$ based select 8 companies (comprising of both Indian and MNCs) which are in existence since average 35 years.
\end{abstract}

Keywords: Leadership, Leadership Development Model, Leadership and Sustained Business Growth, People, BULP Model, Organization

\section{Introduction}

The world in the recent years is experiencing a total transformation in all aspects including - economy, business, technology, people, market, etc., forcing every organization into unchartered territory and enforcing them to redefine what it takes to progress and succeed in this dynamic/ competitive market environment. In fact, the above scenario has enabled organizations / academics to do a comprehensive new research on leadership today.

It is clear that traditional leadership development programs cannot enable the organization (it's leaders) to absorb the impact of unpredictable economic fluctuations,

\footnotetext{
${ }^{1}$ Model not to be copied, reproduced in any form without the permission of the author

${ }^{2}$ Bengaluru is one of the fastest growing cities in the world. With the advantage of geographical safety, climatic condition, high level education standard, wide-spread talent source, etc., Bangalore has been the choice of many Fortune 500 Indian and Multinational organizations. Professionals working here are of global standards in terms of diversity, culture, thinking, capability, capacity, competency, etc.
}

unprecedented market competitive at local/global levels, financial instability of customers/vendors/funding institutions, changing expectations of internal customers and other relevant challenges. The leadership development essentially involves building the capacity for group of people to learn their way out of unpredicted problems or unforeseen challenges.

The traditional leadership development programs were observed as individual level skill and training select individual (more so privilege of senior designated person(s)) on traits like inter-personal skills, influencing skills, negotiation skills, developing different kinds of leadership style, etc. It was propagated as high level rewards and recognition program for an individual senior employee.

Today, the scenario has completely changed ${ }^{\mathrm{i}}$. Every talent is seen as potential leader and the leadership is seen as an effective system design which runs as a continuous development program to improve overall effectiveness of organizational performance and also as an organizational capability to deliver - a) speed in decision making b) execution excellence c) consistent profitability and productivity d) focused positive results to customers/vendors/ stakeholders/employees e) change management or transformation.

\section{Methodology}

The Research design is focused on two class of employees i.e., practicing leaders and leaders-in- pipeline, to capture their observation, comments and experience with regard to leadership development practices in their respective organizations, to check whether they see a real commitment from the organization in terms of proper budgeting for such programs, regularity, outcome tracking, creating long term and varied career opportunity, what are its implications on engaged workforce, progressive business performance and overall growth of the organization.

The data sample consisted of collecting inputs through administering questionnaire among 350 employees consisting of 251 non-management cadre and 99 management cadre (refer Table 2) from 8 select companies $^{3}$ (refer Table 1) based at Bangalore. Bangalore

${ }^{3}$ Considering that Leadership is a common phenomena across all kinds of business and that it's influence is since thousands of 


\section{International Journal of Science and Research (IJSR) \\ ISSN (Online): 2319-7064 \\ Index Copernicus Value (2013): 6.14 | Impact Factor (2014): 5.611}

is seen as a international cosmopolitan city which has well established organizations from across the globe and the workforce consists of people from various States of India and Cities of various countries (at Multinational Companies). Further few criteria for selection of companies (as of FY 2014) included - their historical existence in Bangalore for more than 5 years, minimum employee population of 250 , minimum turnover of INR $250 \mathrm{cr}$ as of FY 2013, consistent overall organizational growth in the past 5 years and Leadership Development as a formal practice of the organization.

The overall statistical data from the research study is as follows:

Table 1: Name of Participating Company

\begin{tabular}{|c|l|}
\hline Sl No & \multicolumn{1}{|c|}{ Company Name } \\
\hline 1 & Computer Science Corporation \\
\hline 2 & Himalaya Wellness \\
\hline 3 & Schneider Electric Co. \\
\hline 4 & Professional Access \\
\hline 5 & First Source (I) Pvt Ltd \\
\hline 6 & TVS Motors \\
\hline 7 & TTK Prestige Ltd \\
\hline 8 & Shimizu Corporation P Ltd \\
\hline
\end{tabular}

Table 2: Job Levels of Participants

\begin{tabular}{|c|c|c|}
\hline Sl No & Job Level & No. of Employees \\
\hline 1 & Staff & 15 \\
\hline 2 & Junior Management & 79 \\
\hline 3 & Middle Management & 157 \\
\hline 4 & Management & 76 \\
\hline 5 & Senior Management & 23 \\
\hline \multicolumn{2}{|c|}{ Total Employees } & $\mathbf{3 5 0}$ \\
\hline
\end{tabular}

\section{Type of Company}

Of the total population covered, around $40 \%$ of the respondents were from multi-national companies (MNC)

years, the researcher focused in reaching two extreme of industry growth of past century - one the manufacturing industry and the other from new age Information Technology industry. The IT/ITes companies were selected on random sampling basis from Nasscom website database and the Manufacturing companies were chosen from internal database of Customs department. Further filtering was done based on the age factor of the chosen organization i.e., the companies that exists in India since 5 years as of April 2013 were chosen. Of the available companies, the subsequent choice was based on sales turnover of the organizations wherein total turnover as of $31^{\text {st }}$ Mar 2013 was @ INR 250 crores and above. The companies selected were from both Indian company and India based multi-national companies (MNCs). This was to get different perspective of employees from different set of environment. The final filtering was based on the size of employee strength of 250 and above.

Based on the above exercise, the Researcher got the list of 32 companies and established connects with HR people of these organisations in all confidentiality. Of these, 15 organisations confirmed that Leadership Development focus exists in their organisation as a formal practice. However, of these, only 8 organisations gave the official consent for the researcher to do the data collection study on the research theme. based organizations and the $60 \%$ were from Indian business house. The study intends to showcase that the structured Leadership Development Program' exists in both types of company set-ups. The researcher intends to give pathways (scope) for future in-depth research on contingency coefficient between Leadership Development Programs in Indian vs Multinational organizations based in India.

Table 3: Participating Company Type

\begin{tabular}{|c|c|c|c|}
\hline \multirow{2}{*}{} & \multicolumn{2}{|c|}{ Company Type } & \multirow{2}{*}{ Total } \\
\cline { 2 - 3 } & Indian & MNC & \\
\hline Employee & 143 & 108 & 251 \\
\hline Management & 62 & 37 & 99 \\
\hline Total & 205 & 145 & 350 \\
\hline
\end{tabular}

\section{Education Background}

There are various management theories on Leadership which explains that Leadership is the inherent birth quality and there are theories which claims that Leadership is taught. The researcher did not intend to focus on either of that but intend to highlight the statistical data that $70 \%$ of the respondents in management or leaders in pipeline category are post graduates. This is just indicating that both organizations and people (current/pipeline leaders) have chosen higher qualification as one of the way to reach Leadership levels/roles. Post the globalization era, it has become inevitable for every leader to understand business at global standards and elevate their employees to work at global competitiveness. Today, the education gives one level of exposure to international standards in any area of the business functions.

Table 4: Education Background of Participants

\begin{tabular}{|c|c|c|c|c|c|}
\hline & \multicolumn{4}{|c|}{ Education } & \multirow[b]{2}{*}{ Total } \\
\hline & PUC/ITI & Diploma & Graduate & $\begin{array}{c}\text { Post } \\
\text { Graduate }\end{array}$ & \\
\hline Employee & 1 & 7 & 93 & 150 & 251 \\
\hline Management & 0 & 1 & 11 & 87 & 99 \\
\hline Total & 1 & 8 & 104 & 237 & 350 \\
\hline
\end{tabular}

\section{Gender}

One of the major influences of globalization is on encouraging gender diversity and equal employment opportunity. Especially in the Indian context, it has been talked frequently that not many female are in Leadership positions in corporate sector. The researcher through this statistical data intends to confirm that $23 \%$ of the respondents are in leadership role / leaders in pipeline calibre in these 8 organizations. The below data would enable future research study on gender diversity impacting the LDP and their influence on business growth and people engagement.

Table 5: Gender based Respondents

\begin{tabular}{|c|c|c|c|}
\hline & \multicolumn{2}{|c|}{ Gender } & \multirow{2}{*}{ Total } \\
\hline Employee & Male & Female & \\
\hline Management & 190 & 61 & 251 \\
\hline Total & 80 & 19 & 99 \\
\hline & $\mathbf{2 7 0}$ & $\mathbf{8 0}$ & $\mathbf{3 5 0}$ \\
\hline
\end{tabular}




\section{International Journal of Science and Research (IJSR) \\ ISSN (Online): 2319-7064}

Index Copernicus Value (2013): 6.14 | Impact Factor (2014): 5.611

\section{Hypothesis}

The study tries to test the following hypothesis:

1.H1: There will be differential perception on Leadership Development - it's impact on Business Growth and Employee Engagement.

2. H2: Management and employees differ significantly in their perception on Leadership Development Program (LDP) and its impact on Business Growth and Employee Engagement

3. H3: Male and female respondents differ significantly in their perception on LDP and its impact on Business Growth and Employee Engagement

4. H4: Respondents with different educational levels differ significantly in their perception on LDP and its impact on Business Growth and Employee Engagement.

5. H5: Respondents at different job levels may differ significantly in their perception on LDP and its impact on Business Growth and Employee Engagement

6. H6: Respondents working in Indian organizations and MNCs differ significantly in their perception on LDP and its impact on Business Growth and Employee Engagement

\section{Data Collection}

There were around 60 questions ${ }^{4}$ to enable respondents to understand the comprehensive outlook and touch points of structured leadership development practice in a given organizational context. These questions were compartmentalized under main categories of:

1. Organizational Involvement perspective

2. Business Growth perspective and

3. People Engagement perspective

The test results gave positive indicators for the Researcher to further classify the questions under 15 factors. As per the Factor Analysis report, the questionnaire was further segmented under the following 9 factors:

\footnotetext{
- Leadership Development (driven by the management)

- F1 = Organizational Systematic Approach (OSA)

- F2 = Organization's Intervention (OI)

- F3 = Organizational Commitment (OC)
}

- Leadership Development and it's impact on overall 'Business Growth

- F4 = (it has) Enabled shared responsibility (ESR)

- F5 = (it's linkage to) Business Goals and Performance Outcome (BGPO)

- Leadership Development and it's influence on creating environment for overall 'People Engagement'

- F6 = Communication and Coordination (among all hierarchies)

\footnotetext{
${ }^{4}$ The researcher tested the internal consistency and accuracy of
this research by applying Cronbach's alpha. The alpha value was

${ }^{4}$ The researcher tested the internal consistency and accuracy of
this research by applying Cronbach's alpha. The alpha value was at 0.956 (1.0 is perfect) indicating high consistent and accurate description of all 63 questions.
}

F7 = Career Development (impact on self and other's growth path)

- F8 = Trust and Transparency (open and positive environment)

- F9 = Delegation and Ownership (empowered employees with accountability)

The responses received from the survey were on the 5point scale of Strongly Agree to Strongly Disagree' with "Can't Say' at the midpoint. Further, the responses were categorized as No (strongly disagree/disagree)', Neutral (can't say)' and _Yes (agree/strongly agree)' responses.

\section{Study Limitations}

1. The inputs collected through questionnaire as well the personal interview may offer very subjective and biased statements/comments of the participant.

2. Depending on organization culture and the target leader, the potential participate may resist in offering actual inputs about the leader / leadership system in their organization.

3. Lack of structured leadership development program may create absolute vacuum in the minds of middle management managers and thus enable confused statement(s) from them during personal interviews with the researcher

4. Organization(s) lacking measurement and metrics system linked to leadership system may not offer required data and would jeopardize researcher's objective towards analyzing leadership impact on business and people engagements.

5. The situational environment prevailing in an organization at the time of researcher's interview period may give scope of unusual/unrealistic/situation based responses from the target participants and would thus mislead the data input itself. 


\section{International Journal of Science and Research (IJSR) \\ ISSN (Online): 2319-7064 \\ Index Copernicus Value (2013): 6.14 | Impact Factor (2014): 5.611}

\section{Research Findings}

Table 6: Descriptive statistics for mean scores obtained for each LDP factor and their ranking - Frequency Analysis Factors of overall respondents

\begin{tabular}{|c|c|c|c|c|}
\hline Factors & Mean & $S D$ & Yes $\%$ & Rank \\
\hline Organizational Systematic Approach & 64.08 & 13.28 & 71.21 & 8 \\
\hline Organization's Intervention & 51.08 & 11.64 & 79.93 & 4 \\
\hline Organizational Commitment & 40.40 & 9.52 & 83.22 & 2 \\
\hline Enabled Shared Responsibility & 29.62 & 4.06 & 81.95 & 3 \\
\hline Business Goals and Performance Outcome & 36.51 & 5.82 & 84.21 & 1 \\
\hline Communication and Coordination & 30.42 & 19.45 & 76.84 & 5 \\
\hline Career Development & 28.19 & 7.08 & 69.14 & 9 \\
\hline Trust and Transparency & 34.86 & 12.32 & 73.21 & 6 \\
\hline Delegation and Ownership & 30.40 & 14.60 & 72.86 & 7 \\
\hline
\end{tabular}

Table 7: Co-relation Matrix

\begin{tabular}{|c|c|c|c|c|c|c|c|c|c|c|}
\hline Components of LDP & & OSA & OI & $\mathrm{OC}$ & ESR & BGPO & $\mathrm{C} \& \mathrm{C}$ & $\mathrm{CD}$ & TT & $\mathrm{DO}$ \\
\hline \multirow{2}{*}{ Organizational Systematic Approach (OSA) } & Correlation & 1 & $.712^{* *}$ & $.494^{* *}$ & $.547^{* *}$ & $.557^{* *}$ & $.473^{* *}$ & $.641^{* *}$ & $.572^{* *}$ & $.627^{* *}$ \\
\hline & Significance & & .000 & .000 & .000 & .000 & .000 & .000 & .000 & .000 \\
\hline \multirow{2}{*}{ Organizational Intervention (OI) } & Correlation & & 1 & $.555^{* *}$ & $.525^{* *}$ & $.510^{* *}$ & $.473^{* *}$ & $.569^{* *}$ & $.542^{* *}$ & $.571^{* *}$ \\
\hline & Significance & & & .000 & .000 & .000 & .000 & .000 & .000 & .000 \\
\hline \multirow{2}{*}{ Organizational Commitment (OC) } & Correlation & & & 1 & $.491^{* *}$ & $.375^{* *}$ & $.359^{* *}$ & $410^{* *}$ & $.528^{* *}$ & $.466^{* *}$ \\
\hline & Significance & & & & .000 & .000 & .000 & .000 & .000 & .000 \\
\hline \multirow{2}{*}{ Enabled Shared Responsibility (ESR) } & Correlation & & & & 1 & $.667^{* *}$ & $.598^{* *}$ & $.540^{* *}$ & $.537^{* *}$ & $.592^{* *}$ \\
\hline & Significance & & & & & .000 & .000 & .000 & .000 & .000 \\
\hline \multirow{2}{*}{ Business Goals and Performance Outcome (BGPO) } & Correlation & & & & & 1 & $.428^{* *}$ & $.562^{* *}$ & $.505^{* *}$ & $.527^{* *}$ \\
\hline & Significance & & & & & & .000 & .000 & .000 & .000 \\
\hline \multirow{2}{*}{ Communication and Coordination (CandC) } & Correlation & & & & & & 1 & $.602^{* *}$ & $.590^{* *}$ & $.717^{* *}$ \\
\hline & Significance & & & & & & & .000 & .000 & .000 \\
\hline \multirow{2}{*}{ Career Development (CD) } & Correlation & & & & & & & 1 & $.698^{* *}$ & $.710^{* *}$ \\
\hline & Significance & & & & & & & & .000 & .000 \\
\hline \multirow{2}{*}{ Trust and Transparency (TT) } & Correlation & & & & & & & & 1 & $.695^{* *}$ \\
\hline & Significance & & & & & & & & & .000 \\
\hline \multirow{2}{*}{ Delegation and Ownership (DO) } & Correlation & & & & & & & & & 1 \\
\hline & Significance & & & & & & & & & \\
\hline
\end{tabular}

(Source: Survey data)

**. Correlation is significant at the 0.01 level (2-tailed)

This factor classification exercise and the findings triggered the researcher to author this Research paper and publish the BULP Leadership Development model.

\section{BULP Model}

Our BULP model is based on extensive research done including collection of primary data at various organizations through initial sampling followed by questionnaire administration, personal interviews with a number of CXOs and non-management employees. It is also the result of investing sufficient time at library, participating in various seminars/conferences on the subject, referring various subject related journals and interacting with like-minded experienced professionals especially in the HR network.

If one can see this model as a guideline, it provokes enormous links and thoughts among the drivers of leadership development programs, to integrate various touch points of organization-business-people and show the importance of absolute integration among these 3 touch points.
Leadership is one of the ancient topics - spoken, talked, discussed, debated, exercised with varied models and approaches. Still it remains as most challenging, dynamic and hot topic - as leadership matters a lot for every organization. Incidentally, leadership is one of the most researched and written about subject in the world. In majority instances, leadership development is referred as developing leader's (person's) traits, styles, qualities, competencies and brand.

The author has tried to give a different dimension to leadership development through this model. The leadership is an organizational capability and capacity gained through systematic honing of leaders (practicing and pipeline) in major touch points including people engagement and business performance. Within leadership, the leaders are in two segments - one is a practicing leader (senior management cadre), expected to demonstrate the leadership skills through complete involvement in designing systematic approach, defining interventions and showcasing commitment at an organizational level, as part of the $1^{\text {st }}$ phase of leadership development journey. The $2^{\text {nd }}$ phase of the journey is about positive environment created with regard to communication and coordination, career 


\section{International Journal of Science and Research (IJSR) \\ ISSN (Online): 2319-7064 \\ Index Copernicus Value (2013): 6.14 | Impact Factor (2014): 5.611}

development, trust and transparency, and delegation and ownership, which supports developing leaders to nurture them in building the appropriate culture within the organization. The $3^{\text {rd }}$ phase of the journey is about how the leaders can involve in defining the acceptable business goals and achieve expected performance outcome periodically, through shared responsibilities among employees.

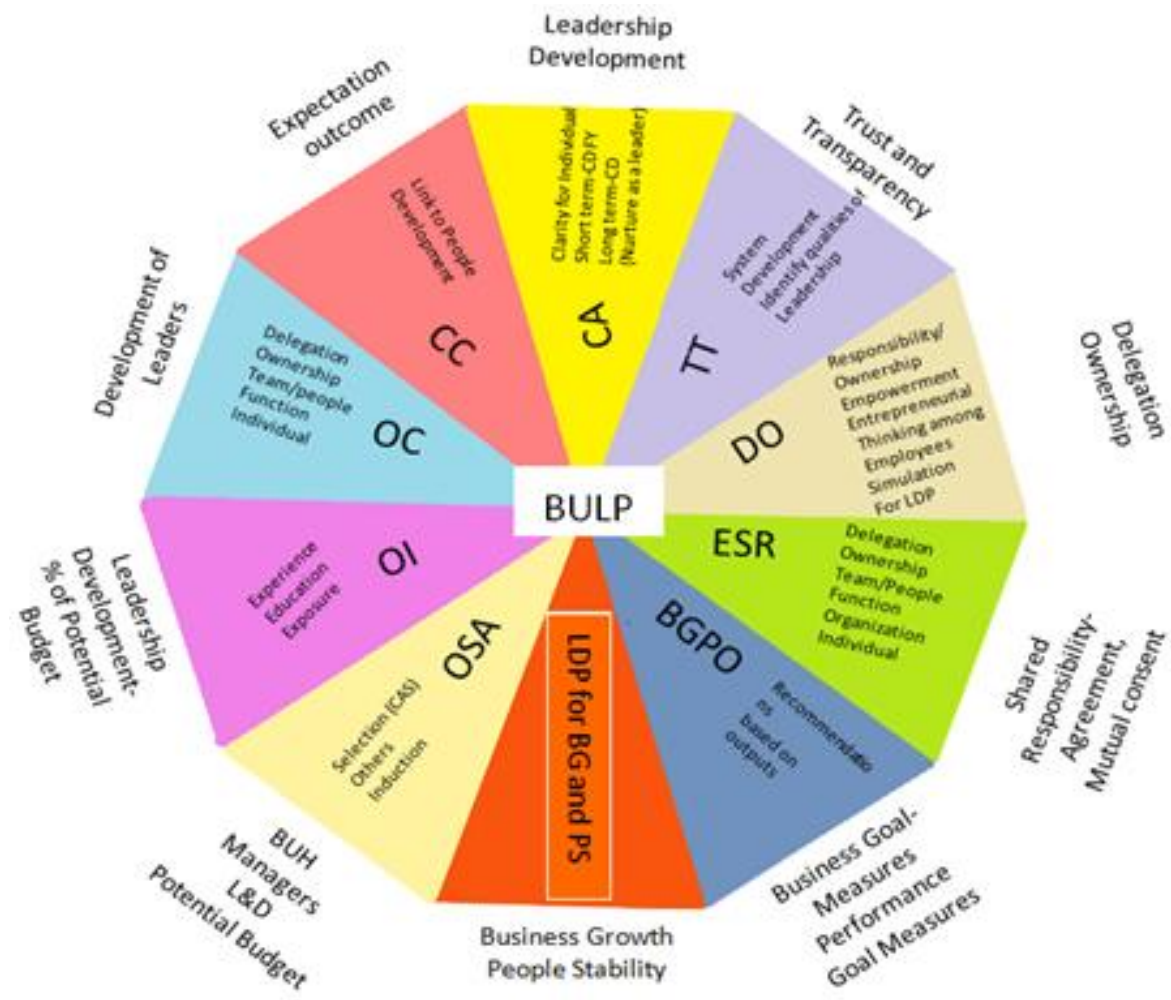

Figure 1: BULP Development Model - by Soumya R S in 2015

Let us understand this model in detail through the below 9 factors and it is recommended that every leader has to sequentially cross-through each petal, to acknowledge himself/herself as a matured leader. Depending on the maturity of various assessment reports (including, but not limited to - interview evaluation of newly joined, performance appraisal feedback sheet, assessment centre report, 360 deg feedback, etc., ), organizations would select employees for leadership development journey or it's about how leadership development program in an organization moulds the leaders (practicing and potential).

\section{Factor 1: Organization Systematic Approach (OSA)}

It's about setting a proper play ground to facilitate world class football/cricket match. The organization(s) which are serious, committed and matured would build following set-ups at the play ground:

Vision-Mission-Values - Fundamental expectation between organization and employees to set the ball rolling in the right direction. Any talent in the organization would fundamentally look at long term visibility of the organization and it's preparedness in all respects to meet the strategic goals. Defined organizational value(s) is something which every leader has to imbibe and demonstrate in every internal and external context.
Defined Competencies - Leadership competencies should have a tight linkage to the overall strategy and strategic priorities of the organization. A potential leader should be made aware of these and guided by the senior leaders to imbibe these in the course of leadership development and apply appropriately in all instances.

Well defined and structure leadership development program - Any development program is not an adhoc but a planned one. Such structure will provide entire clarity on - content of the continuous development, interventions, milestones (including start and end dates of each program), expected outcome, role and responsibilities of program owners and of participants. This enables every developing leader to prepare better well before start of the development journey.

Leadership capability - Companies have become great because of their leadership team (visionary to execution). It's about demonstrated abilities of senior leaders which has directly supported organization's healthy growth internally (retention and attraction of talent) and externally (profitable business growth and expansion). It's a real boost for the upcoming leaders within the organization to rely on their organization's leadership capability and seen them as mentor coach in their leadership development journey. 


\section{International Journal of Science and Research (IJSR) \\ ISSN (Online): 2319-7064 \\ Index Copernicus Value (2013): 6.14 | Impact Factor (2014): 5.611}

Defined Leadership competencies - are leadership skills and behaviors that contribute to superior performance. By using a competency-based approach to leadership, organizations can better identify and develop their next generation of leaders. DLC has to be regularly shared among developing leaders to support their own individual development plans and preparedness.

Measurements - Leadership is intangible. But their demonstrated action impacts the organizational performance, which in turn can be measured. From the study context, the successful organizations tracks leader's intervention outcomes like periodical business growth, employee satisfaction index and retention \% of talent in all circumstances of organizational growth phase. Outcome of the entire LDP effort not measured at periodic intervals, could only create feeling of liability in long run.

\section{Leadership development program - Matured} organizations have well defined guideline and criteria for selection of potential leaders. This enables employees to do self evaluation and prepare themselves either to take the leadership path or not. Well structured selection process enables majority of employees to respect the leadership development program and system.

Responsibility and Accountability - This applies to all employees within the organization. But it is even more imperative that the leaders (practicing and potential) are aware of their role, responsibility and accountability while exhibiting their leadership abilities from time to time.

\section{Factor 2 - Organizational Intervention (OI)}

Mentor / Coaching - One of the approaches in developing leaders is leadership coaching and mentoring. This intervention is powerful for those leaders looking for their own behavioural change, improve personal productivity and focused career growth. Organizations have started realizing that senior leaders can be trained to become Mentor Coaches and internally support coaching needs of potential (developing) leaders. Both Coaching and Mentoring exercises are on one-on-one basis and hence require commitment of both Coach/Mentor and Coachee/Mentee. The organization owns the responsibility as a facilitator and sponsor of such intervention. The coach/mentor stands on his/her wisdom whereas the developing leader(s) is committed to get clarity on priorities and attain professional/personal direction and define mile-stone based action plans for a mutually beneficial accomplishment(s).

Training and Development - Having identified the potential leaders and that there are set of defined competencies, it is imperative for the organization(s) to facilitate training for target talent (developing leaders) in order to attain the relevant competency as part of the leadership development journey. New approaches to development activities include allocating special assignments, enabling action learning through simulation programs and facilitating web based educational activities.
Leadership Capacity building - It is well debated and known to most CEOs that leaders are in short supply as organizations looking at building this capability to achieve higher competitiveness in the industry. Leadership is very sensitive and inappropriate hiring of leaders from the market could cause damage to the organization. Hence Leadership Development is a continuous process ${ }^{5}$ of developing new set of talent at defined frequency and ensure sufficient pool of leaders are available within to drive the organization to the newer heights.

Mobility - One of the major interventions from the organization is designing growth plan for the members under leadership development program and that should happen through systematic movement of identified talent(s) both horizontal and vertical. This means there should be a proper succession planning framework for not only the key positions, but also for developing leaders ${ }^{6}$ and enable target talent to occupy role either at elevated position or peer level position, within the department or cross functional department or different units of the group. The senior leaders should offer required support required by the target talent(s) and also monitor their exhibited capability in the new role.

\section{Factor 3 - Organizational Commitment (OC)}

The success of the leadership development depends on serious commitment ${ }^{6}$ of the board and senior management (senior leaders) at all times. If organization expects talent to commit their long term association as part of leadership development journey, the people around also expects organization (management) to demonstrate their commitment through proper LDP calendar, systematic budgeting, building leadership culture, Employer Branding, etc.

Budget - The planning and budgeting are considered as very important aspect in leadership development. Right from appropriate talent hiring process (using relevant assessments to understand potential leadership qualities of the candidates) to identifying right internal talent (through various assessment centres) to organising various talent group development programs (integrated development including specific training, certifications, higher education, special assignments, etc.) to individual development interventions (coaching/mentoring, etc.) and provision for rewards and recognitions - the senior leaders (may be LandD head as a owner of the process) have to do costing exercise and arrive at total cost of leadership development program. Organizations which believe in the benefit of leadership development, do keep dedicated fund for leadership development irrespective of business/market scenario. Ultimately, leadership development is a long term strategy and a continuous process.

\footnotetext{
5 “As Douglas McGregor says - leadership development is an agricultural process wherein the process of sowing the seed to reaping the fruit has a defined time factor and one has to patiently wait to get their fruit."

"Unless commitment is made, there are only promises and hopes; but no plans"-Peter F. Drucker
} 


\section{International Journal of Science and Research (IJSR) \\ ISSN (Online): 2319-7064 \\ Index Copernicus Value (2013): 6.14 | Impact Factor (2014): 5.611}

Leadership development as a Culture - Among various factors of culture building, organizations demonstrates systematic honing of leaders as one of their culture. This also creates specific internal employer branding and gives confidence to aspiring talent to dream their career growth within their organization. The senior practicing leaders within the organization have to demonstrate their commitment towards upbringing their potential (and identified) leaders.

Leadership measured - The real motivation and inspiration for the developing leaders is when they understand that their management (senior leaders) periodically (and seriously) tracks the outcome of leadership development activities in various priority aspects of organizational business like productivity, profitability, turnover, people retention, resource utilisation, customer satisfaction levels, quality standards of deliveries, operational cost efficiency, etc. It is also about how management (senior leaders) intervenes for corrections or appreciation, where required and the way they join hands with developing leaders in such exercises.

Leadership Development as a true brand - Any practice becomes a brand when it occupies a place in the heart and minds of people (employees, customers, vendors and aspiring candidates) and they dream to be part of such happening environment. For all these stakeholders, it acts like elements of trust, confidence, faith, delight, positivity, inspiration, commitment and guaranteed output standards. For organizations which are committed to leadership development programs as a regular system, the positive branding comes automatically. Among many Indian organizations, Tata Group, Wipro, Infosys, Aditya Birla are some of the commonly referred brands in leadership development practice.

\section{Factor 4 - Communication and Coordination (CC)}

Good leader understands the importance of giving the message in a maximum simplicity to make it simpler for the group of people to decode it in the similar way that they want it to be interpreted. Leaders rather than using their leadership style, can focus on purpose why they want to communicate with people. Communication should be largely worked with impact factor so that it can stay with people for long duration by different ways and means to repeat the message with different modes and methods.

Communication is nothing but transferring the information from one place to another or sharing to the group of people. It looks simple but not so. It is a complex phenomenon when we associate the communication between two individuals, as there will be error in coding and decoding the same message with the interpretation of personal beliefs. Same communication becomes even more complex in nature when it is associated with the group and can create a challenging atmosphere as each person would like to put forth their own decoded messages.
The context for a leadership team could be anything including:

1. Sharing about periodical business goals;

2. Sharing business growth (short/long term) plans, achievements or periodical performance;

3. Repeat awareness on shared Vision/Mission/Goals of the department/organization/group;

4. Periodical survey on various internal programs, survey results and action planning; and

5. Clarity on role, responsibility and accountability at individual and group level.

Communication has its significant value to bring the satisfied atmosphere within the organization. Effective communication definitely will impact population at all levels. It is essential that a leader is completely nurtured to communicate effectively (and not just efficiently). Especially for a leader, it is all about - what, where and how to say, who are the audience and how to create twoway platform to exact understanding of the information shared/transferred.

The communication at leadership level comes with challenge and a barrier where leader will not be able to see or hear what's happening among the people. As they move up in the ladder the factor of distances comes into existence. So it becomes essential for leader to reduce this distance factor by reaching the target population at their level. Coordination ${ }^{7}$ is challenging because it has tendency of natural spill-over. Aligning teams to share the information is an art from leadership perspective.

Creating the balance between communication and coordination is very essential to create sustainable approach to fulfill the emerging demands in complex organizational environment. The main aim of communication and coordination here is to:

1. Construct an environment to engage, attract and retain the real talent $\mathrm{HPP}^{8}$.

2. Have a steady course at the time of transition, change management ${ }^{9}$ and at the phase of difficulty, maintain a steady course through times of transition and difficulty.

3. Take the leading edge in change over business with continuous innovation and renewal.

\footnotetext{
${ }^{7}$ Leader as a communicator, In Dewan and Myatt (2008), followers would like to coordinate, but cannot because they do not know what others believe. Thus, the role of the leader is to communicate information that can facilitate coordination ${ }^{8} \mathrm{HPP}$-High performing people

${ }^{9}$ What makes -nimble" companies nimble? The ability of leaders to keep people always aware of the score, tuned into what's important and why, is crucial. Each new brand promise must be matched by the ability of the organization and its workforce to deliver on that promise and to tive the brand." communication strategies for sustaining an emphasis on doing the right things right. Leaders strategize the communication with clarity and urgency - and to engage other managers to follow suit.
} 


\section{International Journal of Science and Research (IJSR) \\ ISSN (Online): 2319-7064}

Index Copernicus Value (2013): 6.14 | Impact Factor (2014): 5.611

Factor 5 - Career Development (CD)

Career development in the organization context is a process of preparing the employees to make a contribution to the organization for future. It is a must for the organization to define Career Development Plans especially for high potential talent and leaders in pipeline, to attract their engagement with the organization on the long term basis. This in turn expects organization to have a well designed organization structure, succession planning and short/ long term business strategies.

The organization should have wide spread career development plan which would be based on a) hierarchy b) skill and competency level (technical/functional) c) behaviour competency level d) business line based and e) leadership based. On the other hand, such transparent system sets expectation for the target employee(s) to focus on her/his individual development plans (technical/functional and behavior competencies) and set their own target to achieve each mile stone.

A clear career development plan enables employee(s) to be engaged in reaching their own career mile stones and benefits organization to define vertical/horizontal moves as per structured succession planning for target positions / new opportunities.

The structured career move for potential leaders/high potential performers could happen through

1. Scientifically proven assessment centres

2. Appreciative enquiry - discover, dream, design and deliver

3. Supporting higher education / add-on qualification (skill certificates, etc.)

4. Job enrichment - to acquire more relevant competencies

5. Job redesign - suiting the up-skilled employees with greater autonomy

6. Job change - challenging assignments for high potential employees

7. Promotion - to take higher role and responsibilities

8. Internal support - assign mentor/coach for appropriate direction/clarity

\section{Factor 6 - Trust and Transparency (TT)}

Trust $^{10}$ is an ability of a leader to be transparent, to create the confidence in a team for healthy and positive work

\footnotetext{
${ }^{10}$ Stephen M. R. Covey in his book "The Speed of Trust" mentions - Trust is a function of both character and competence". Trust and transparency environment enables people to work together effectively. The outperforming team always demonstrates the state of good intention and creates the safety among group members including positively shadowing each other where/when required. As Covey suggests, following demonstrated behaviours among leaders would strengthen their relational trust with their members. These are: talk straight, demonstrate respect, create transparency, right wrongs, show loyalty, deliver results, get better, confront reality, clarify expectations, practice accountability, listen first, keep commitments and extend trust.
}

environment $^{11}$. It is sharing knowledge, skills and experience in work culture and caring team member's performance to reach higher goals. Beyond the internal system, the culture of trust and transparency enables clients and vendors also to work closely with the organization, to discuss the business issues/challenges and collaborate in finding achievable solutions for the benefit of all of them.

- Helping employees understand the company's overall business strategy.

- Helping employees understand how they contribute to achieving key business objectives.

- Sharing information with employees on both how the company is doing and how an employee's own division is doing -- relative to strategic business objectives.

In today's professional world, employees are well educated and self respected. Employees look for mutual respect and they look for leaders who can equally share knowledge and wisdom. Leaders can adapt to technology to build the transparent systems and processes related to employees in the organization and adapt personal connect to gain the trust among their members. The personal connect gives positive space for a leader in the following way:

1. Realistic Bonding: TT in a work environment helps reducing distance between leader and group members. This in a way helps in having a healthy relationship, mutual respects and reduced conflicts among the members.

2. Bugs are removed: TT in a work environment removes the defensive attitude, falsification/manipulations among the employees and rather enables leader-group members to solve the problem through combined effort.

3. Healthy Teams built with ease: TT influences responsibility and accountability among members to achieve the defined shared goals. Creating the platform to open discussion will enhance the culture within the organization to develop the bold and fearless environment. Team will believe in working together and getting the smarter ideas collaboratively and leads to great innovation in the stream, which is essential to create a different brand image for the organization. Team members will become real ambassador to brand the organization in all permitted platforms.

4.High Performance Work System developed: The leaders can anticipate higher level performance from the (sy) energized group members.

\footnotetext{
${ }^{11}$ Hay's study examined over 75 key components of employee satisfaction. They found that:

- Trust and confidence in top leadership was the single most
reliable predictor of employee satisfaction in an

- Trust and confidence in top leadership was the single most
reliable predictor of employee satisfaction in an organization. - Effective communication by leadership in three critical
areas was the key to winning organizational trust and Effective communication by leadership in three critical
areas was the key to winning organizational trust and confidence:
} 


\section{International Journal of Science and Research (IJSR) \\ ISSN (Online): 2319-7064}

Index Copernicus Value (2013): 6.14 | Impact Factor (2014): 5.611

Factor 7: Delegation and Ownership (DO)

Leadership is a role and not the designation. The delegation ${ }^{\text {"12 }}$ is a complex concept and enables people to interpret in their own way. Hence from the leadership development perspective, the organization has to define the framework for Delegation and Ownership. In a sense, it's about _what to delegate and what not' and how much to expect from the accountability and responsibility perspective'.

The empirical research indicates that delegation and ownership' is one of the most effective ways of enabling employees at different levels to use their creativity and innovative abilities to improve the overall performance of the organization that they work for and the quality of their own work life.

The global research shows that Delegation and Ownership increases trust and commitment, self motivation and ownership to reduce mistakes/increase pace of work and take ownership for their actions. In such scenarios, the acceptance level for any change management' is very high. In many cases, the business goals/strategies are drawn with the involvement of employees at different levels. To an extent, employees will take charge of self learning, aspirations, goals and growth through appropriate HR intervention. Such culture enables complete alignment of individuals to the vision, mission, values, goals and business priorities of the organization, from time to time and completely enables co-creation on every aspect of organizational short and long term plan of actions.

The Leaders here are expected to understand, apply the DandO as an organization culture and act as a facilitator to achieve the defined objectives.

However, for effective implementation of delegation and ownership, leaders have to assume following challenges and actions to be planned appropriately

- Individual's approach (thoughts, speed of work) vs environment that demands quick business results

- Culture change from control-command to delegateownership

- Assumed performance measures vs clear and explicit performance measures

- Conditional results expected vs individual ability in dando environment.

\section{Factor 8 - Enabled Shared Responsibility (ESR)}

Enabled Shared Responsibility is a multidimensional leadership model. The earlier research has proved that ESR has created high performing work environment in the organization. ESR is an established culture and system in

\footnotetext{
${ }^{12}$ Your most important task as a leader is to teach people how to think and ask the right questions so that the world doesn't go to hell if you take a day off,". (Jeffrey Pfeffer, author of What Were They Thinking?: Unconventional Wisdom About Management)
}

the organizations, where the leaders (practicing and potential) are involved in every step starting from designing and defining the business goals for the organization, to the level of getting their own performance tracking against the agreed goals. In a way, it is all about making every leader as a responsible entrepreneur.

To elaborate, organization involves leaders at all level:

1. In design and defining the long/short term business goals: for the organization. This is to enable the leaders to understand overall planned business growth of the organization and for the individual leader to understand his/her stake in such growth prospects and further, develop plan of action to meet such growth expectation.

2. In empowering them to work around: on resource mobilisation and utilisation, work with their customers directly, creativity and innovation, development and deployment of resources, financial planning, technology intervention, talent management and engagement aspects, etc. Within the overall defined system of the organization, the leader is empowered to play around and manage the show to drive the results/meet the agreed short/long term deliverable.

3. Participation in bringing new dimension: to the overall business approach of the organization, innovate new things; lead the change for transformation (business/people/system/technology/others).

4. Enabling leaders to check their periodical performance: (department/business unit/ business vertical) and applying strategic / tactical measurements required to turn to positive results.

Organizations practicing such system have shown positive results in improving their business performance at every periodicity, in attraction and retention of talent at different levels, new client acquisition, business expansion at different geography, innovation of new products/services, etc.

At the overall organizational level, such practice enables employees to understand the overall business progression of the organization, creates an environment of stability and career growth, financial comfort for every employee, trust and transparency in the data shared, clarity on future growth of the organization and a sense of achievement/belongingness.

\section{Factor 9 - Business Goals and Performance Outcome (BGPO)}

The progressive organizations mould their leaders and pipeline leaders to think like a Chief Executive Officer (CEO)'. There are 4 quadrants that any progressive leader should be (become) familiar with - Finance, People, Products/Services and Market (positioning).

As part of leadership development, the organizations look at harnessing the talent (leaders) in understanding the business" which is most critical for any/every leader, to align to the business prospects. While the senior leadership team sits on designing initial business strategy, they expect 


\section{International Journal of Science and Research (IJSR) \\ ISSN (Online): 2319-7064}

Index Copernicus Value (2013): 6.14 | Impact Factor (2014): 5.611

developing' leaders to join the discussion in framing the business goals.

Many research studies have revealed that lack of alignment across businesses and leaders is the biggest challenge faced across industries and across the globe. Such misalignment at the leadership level results in missed business opportunities, inappropriate business decisions within the organization and inability to respond to the changing business/market needs. This in turn will have direct impact on the overall performance outcome of the organization.

Apart from banking on their functional domain expertise, Leaders have to spend more time and effort in understanding the business competence, business environment, business strategic issues and challenges, and business opportunities. With absolute clarity of these, the leaders have to cascade their understanding and organization's expectation to their group members. Alignment of people at all levels, to the business objectives and goals of the organization is very essential to ensure periodical overall growth of the organization. For this, it is important that the leader has the business acumen first.

In addition, in many organizations, Leaders are encouraged to create culture of innovation. The leadership can look at encouraging idea generation from the employees and reward the ideas (employee) who has given executable idea/s. In today's competitive world, organizations are clear that business goals for a leader includes - improving quality of deliverables (products/services) with optimum utilization of resources, improved efficiency and effectiveness in all operational aspects, improved customer satisfaction and relationship, improving top line turnover on year-on-year basis, improved employee value proposition, improved employer brand (internal and external) and improved talent attraction rate.

Performance outcome is a combination of aligning people passion with business goals. It is imperative that every leader in organization(s) has to be a people leader and work towards getting the group of members aligned to achieve the set business goals of the organization. This requires leaders to imbibe abilities to - motivate people, recognize and reward, coach and mentor, career counsel and support the progression, build the belongingness, harness their capability, etc. Leaders should be flexible to complex adoptive system to pursue individual plans and convert them to reach business goals.

\section{Conclusion}

First and foremost, Leadership Development is not a seasonal activity depending on the financial comfort of the organization. The organization has to develop the culture of developing leaders (current and pipeline) and make it a systematic approach. Leadership Development Program is not an event but a continuous process. Leadership is an organizational capability to create and sustain competitiveness.
Leadership Development is incomplete if the current leaders and leaders in pipeline are not made accountable for both positive business results and talent retention. Here is where they can showcase themselves as role model and influence others to look at greener pastures from time to time.

Adoption of BULP leadership model would help organization to build the automatic approach in identifying potential leader, get a mutual sign-off between practicing leaders and potential leaders for a committed long term journey, enable concerned to fund this movement periodically through proper budgeting, design programs for overall development of select talent, design appropriate career path for these talent with relative growth clarity, enable horizontal and vertical positioning of talent to enlarge their functional and cross-functional exposure.

The leadership team in the organizations today ultimately looks at Returns on Investment on their leadership development program. While leadership capability is intangible and cannot be measured, the business results and performance outcome caused by the actions/interventions of leaders is measured by the organizations. A direct impact on their Profit \& Loss and progressive business growth - is what every organization is looking for from Leadership Development intervention.

As a last word, leadership development is a continuous and long term strategy, to ensure sustained growth of business and people. There is nothing called consistent peak performance and growth. There are various external factors that influence organization's business performance and organization should not pick that hurdle as a reason to slow down the leadership development programs. Keeping the overall framework undisturbed, the organization(s) can customize and develop leadership development programs suiting their overall organizational culture and long term strategy. The leadership development programs should be reviewed by the management and Leadership Development Program drivers periodically to address the changing needs influenced by internal and external factors.

Among all the elements of an organization, leadership is perhaps the most important. Leadership sets direction, impacts culture, defines the norms, controls resources, delivers communication, and designs and distributes rewards. Leadership strategies deserve as much attention as business strategies, but they do not often get it. In great companies, a significant amount of top leaders' time may be devoted to leadership development activities. While leadership is learned, the skills and knowledge processed by the leader can be influenced by their own traits, such as beliefs, values, ethics and character. Knowledge and skills contribute directly to the process of leadership, while the other attributes give the leader certain characteristics that make him or her unique.

\section{References}

[1] Battilana, J., and Dorado, S. 2010. Building sustainable hybrid organizations: The case of 


\section{International Journal of Science and Research (IJSR) \\ ISSN (Online): 2319-7064}

Index Copernicus Value (2013): 6.14 | Impact Factor (2014): 5.611

commercial microfinance organizations. Academy of Management Journal, 53(6): PP 1419-1440.

[2] Besharov L. Marya. and Rakesh Khurana ( $8^{\text {th }}$ Jan 2013) - Leading Amidst Competing Technical and Institutional Demands: Revisiting Selznick's Conception of Leadership - working papers- Havard Business School: PP 3-6.

[3] Christopher Meyer and Julia Kirby, August 3, 2010 "The Big Idea: Leadership in the Age of Transparency, " Harvard Business Review, http://hbr.org/2010/04/the-big-idea- leadership-in-theage-of-transparency/

[4] Dan Schwabel - Contributor, Forbes.com $\left(9^{\text {th }}\right.$ Sept 2013) - Why Companies wants you to become Intrapreneur

http://www.forbes.com/sites/danschwabel/2013/09/09/ why-companies-wants-you-to-become-intrapreneur/

[5] David V Day Feb 2014 - Advances in leader and leadership development: A review of 25 years of research and theory - The Leadership Quarterly $25^{\text {th }}$ Anniversary Issue 1, Vol 25, PP 63-82

[6] Goldsmith M and Howard Morgan; - Eadership is a Contact Sport: The Follow-up Factor in Management Development" Strategy + Business, Published: August 25, 2004 / Fall 2004, Issue 36 PP 2-3

[7] Hii Wei Min, May-Chiun Lo, Ramayah.T. September 2009, Leadership styles and organizational commitment: a test on Malaysia manufacturing industry, African Journal of Marketing Management, Vol. 1(6) PP 133-139,

[8] John Adair. (2009, April). Functional Leadership, NHRD Network Journal, Vloume-2, Issue-2. P 2-7.

[9] Kanter, R. M. (2011, November) - How great companies think differently. Harvard Business Review, November issue PP 66-78.

[10] Kirby, P.C., Paradise, L.V., and King, M.I. (1992). Extraordinary leaders in education: Understanding transformational leadership. Journal of Educational Research, Issue 83(5). PP 303-310

[11] Manasse, A.L. (1986). Vision and leadership: Paying attention to intention. Peabody Journal of Education. Vol. 63 Issue No.1, PP 73-150

[12] Mayfield Jacqueline and Mayfield, Millan: - Eader Communication Strategies Critical to Improving Employee Commitment" American Business Review, June 2002. PP 2-5.

[13] Whetten, D. A., and Mackey, A. 2002. A social actor conception of organizational identity and its implications for the study of organizational reputation. Business and Society, Issue 41: PP 393-414

\section{Author Profile}

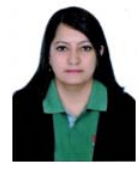

Soumya R.S., Ph.D., Student, Jain University, Address: \#121, Shree, 7th Main, 3rd Cross, Bhavani Nagar, 2nd Phase, Mallathalli, Bangalore-560056, India, E-Mail ID: soumya.mule@live.com, Contact no: +91 9742445454

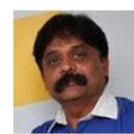

Dr. M. M. Bagali, Professor Management, Head-Ph.D., Program in Management, Jain University, Address: CMS Annex, \#319, 17th Cross, 25th Main, J P Nagar 6th Phase, Bangalore- 560078, India, Mail ID: mm.bagali@jainuniversity.ac.in, Contact no: +91 9880986979 